\title{
Cine e inmigración: Madrid como espacio de encuentro/desencuentro y su representación en Extranjeras de Helena Taberna
}

\author{
Cristina Martínez-Carazo \\ University of California, Davis
}

La España contemporánea, olvidadiza en lo respecta a evaluar su pasado, parece decidida a mantener a pulso una ilusoria homogeneidad carente de soporte histórico. Si a nivel oficial España como nación se construye a base de exclusiones, llámese judío, musulmán, gitano, la herencia cultural y la percepción de la españolidad desde fuera se ocupan de recordar que las huellas del 'otro' permanecen por encima de su desaparición física. Varios críticos han dado en señalar estas exclusiones así como la tensión entre la homogeneidad y la heterogeneidad derivada de la transición de una España franquista autárquica a una España global. Paul Julian Smith analiza la presencia del gitano como "a hybrid subject, both strange and familiar, who is at once a response to and a displacement of Spaniard's confrontation with a more radical otherness: that of global immigration to Spain” (162). José Manuel del Pino revisa el desafío que supone la comunidad gitana para el "nacionalismo españolista del franquismo" (258) a la hora de configurar una “noción homogeneizadora de la identidad española [que] se caracteriza por su desconfianza a toda diferencia” (258). En la misma línea John Hooper observa la necesidad imperiosa por parte de "los nuevos españoles" de enfrentarse a una realidad multirracial después de cinco siglos de aparente uniformidad étnica (424). También Isolina Ballesteros al estudiar la representación de la xenofobia y el racismo en el cine 
español muestra cómo tanto "la construcción del estado español moderno, cuya identidad se define en torno a la depuración de elementos extranjeros en la metrópolis y en las colonias (expulsión de judíos y árabes, exterminio de etnias indígenas), como su mímesis franquista" (206) operan como cimientos del racismo contemporáneo.

La impureza racial, que durante la alta edad Media generó un rico panorama cultural, se vivió a partir de los Reyes Católicos como un estigma y como tal trató de borrarse. Spencer sintetiza del siguiente modo esta estigmatización de la pluralidad racial: "of all nations under heaven I suppose the Spaniard is the most mingled, most uncertain, and most bastardly". ${ }^{1}$ La negación de esta bastardía habría de llegar a su cénit con el proyecto homogeneizador impuesto por el franquismo, empeñado en inculcar en el imaginario colectivo la entelequia de una unidad racial, un pasado glorioso común y un proyecto histórico unidireccional. Con tal intensidad se grabó en España esta impuesta imagen unitaria que, a pesar de las enormes transformaciones sufridas a partir de los regionalismos, de la europeización y de la globalización, el sueño de la unidad racial y cultural parece seguir vivo. De ahí la tensión entre la persistencia de una identidad homogénea heredada y el imperativo de recrearla a luz de la realidad plural del tercer milenio. A esta dificultad para perfilar una concepción inclusiva y armónica de la identidad alude Iman Fox al afirmar que 'nuestro mundo postmoderno y multinacional de transitoriedad institucional encuentra difícil asociar una identidad humana o un sentido del ser con una cultura coherente o con una lengua' (Fox, 210).

A raíz de la integración de España en Europa, de la consolidación de su economía y de la entrada en la órbita de la globalización emerge un nuevo sujeto, el inmigrante, desposeído en la medida en que ocupa los márgenes de la estructura social, y poderoso en 
cuanto que supone un desafío desestabilizador para el poder. A pesar de su presencia en la España actual su inclusión en el proyecto de reconstrucción de la identidad nacional queda aún lejos de la realidad. Si bien es verdad que el español está dispuesto a reinventarse a sí mismo a partir de su recién estrenada pluralidad regional y de su pertenencia a Europa, como bien muestra Richardson en "Hispanic v. European Identity; Where is Spain", resulta innegable que en esta reinvención no cabe aún una dimensión multirracial. Dicha exclusión tiene como contrapartida la omnipresencia de la cuestión de la inmigración en el discurso social, político y cultural español y con especial énfasis en los medios de comunicación que, como indica Isabel Santaolalla, son un referente clave para rastrear "changing patterns in formulations of ethic and cultural identity in contemporary Spain" (56). ${ }^{2}$ La misma autora, refiriéndose a la proliferación de lo que ella acertadamente califica de "ethically loaded images" demuestra que, además de mostrar las transformaciones de la sociedad española, estas imágenes ponen de manifiesto cómo "ideological and rhetorical mechanisms turn representation into a process of production rather than one of simple replication" (56).

A la luz de este enorme impacto que tienen los productos culturales a la hora de formular/reformular la identidad nacional me propongo explorar el documental, Extranjeras, dirigido por Helena Taberna en el 2002, y su modo de tratar la presencia del inmigrante en España. El cine y la novela narran ahora la experiencia de la inmigración abriendo un abanico de representaciones que plasma la multiplicidad de posiciones desde las que se aborda la dialéctica entre los sujetos generadores del discurso y los objetos de representación. Recordemos el creciente número de textos fílmicos y documentales que tratan de modo directo o tangencial el tema de la inmigración, entre ellos Bwana (Imanol 
Uribe, 1996), Taxi (Carlos Saura, 1996), Las cartas de Alou (Montxo Armendáriz, 1990), La sal de la vida (Eugenio Martín, 1995), Flores de otro mundo (Icíar Bollaín, 1999), Balseros (Carles Bosch y Josep María Doménech, 2002), Poniente (Chus Gutiérrez, 2002), Salvajes (Carlos Molinero, 2001), Cosas que dejé en la Habana (Manuel Gutiérrez Aragón, 1997), Saïd (Frances Llorent, 1999), En construcción (José Luis Guerín, 2001), además del mencionado Extranjeras (Helena Taberna, 2002). Igualmente escritores de la talla de Juan Pedro Aparicio (La gran bruma, 2001) Lourdes Ortiz (Fátima de los naufragios, 1998), Eduardo Mendicutti (Los novios búlgaros, 1993), Agustín Cerezales (Perros verdes, 1989), Lorenzo Silva (Algún día, cuando pueda llevarte a Varsovia, 1997) y Julio Llamazares (Escenas de cine mudo (1994), y El techo del mundo (1998) además del guión cinematográfico de Flores de otro mundo, 1999) dan buena prueba de la creciente presencia del inmigrante en la literatura actual. Además varios escritores se han acercado a este tema desde la prensa (Juan Goytisolo, Manuel Vázquez Montalbán y Mario Vargas Llosa entre ellos) abriendo un debate puente entre la creación literaria y los medios de comunicación.

Partiendo de estas premisas pretendo analizar en este artículo cómo la representación cinematográfica de comunidades urbanas, en concreto del Madrid reflejado en el documental Extranjeras (2002) de Helena Taberna, articula las cuestiones relacionadas con la otredad, con el género y con la experiencia postcolonial. Exploro así el modo en que este film plantea una reflexion sobre la presencia del inmigrante en Madrid a partir de la resistencia, la negociación y el cuestionamiento presentes en el texto, y el impacto que tiene dicha reflexión en el modo de perfilar el encuentro/desencuentro entre los españoles y los recién llegados. Desde este ángulo resulta especialmente significativo 
evaluar las respuestas del documental a este Madrid actual, global y postmoderno, y en concreto su utilidad a la hora de analizar su metamorfosis a partir de su representación en el celuloide. A su vez subrayaré las limitaciones que encierra el documental como género a la hora de desvelar la realidad tanto por lo que tiene de "performance" como por la problemática autenticidad de los productos culturales centrados en el otro pero construidos por voces hegemónicas. Como afirma Bill Nichols en Blurred Boundaries "Traditionally, the word documentary has suggested fullness and completion, knowledge and fact, explanations of the social world and its motivating mechanisms. More recently, though, documentary has come to suggest incompleteness and uncertainty, recollection and impression, images of personal worlds and their subjective construction...

Documentary and fiction, social actor and social other, knowledge and doubt, concept and experience share boundaries that inescapably blur" (1).

Extranjeras se inscribe claramente en la tradición crítica del documental español en la medida en que, como muestra Kinder en "Documenting the National and Its Subversión in a Democratic Spain", este género se asoció desde un principio a cuestiones de identidad local y a la dialéctica entre 'insiders y outsiders'. Además el film de Helena Taberna conecta también con la línea subversiva y la carga política que el documental heredó del franquismo (recordemos que en 1942 se prohibió todo documental que no fuera el NO-DO) e incluso del pre-franquismo (pensemos en Las Hurdes, tierra sin pan, 1932, dirigido por Buñuel). Esta misma subversividad se mantiene viva en los documentales de la España democrática, en un primer momento como medio para repensar la historia (El desencanto (1976) de Jaime Chavarri, Canciones para después de una guerra (1971) y Madrid (1987) de Basilio Martín Patiño, La vieja memoria (1977) 
de Jaime Camino) y en la actualidad como instrumento para reflexionar sobre el presente y mostrar lo que la historia tiene de cambiante y de inaprehensible (En construcción (2001) de José Luis Guerín, Extranjeras (2002) de Helena Taberna, Asaltar los cielos (1995) de José Luis López Linares y Javier Rioyo, La pelota vasca: la piel contra la piedra (2003) de Julio Medem, Gala (2003) de Silvia Munt. En este marco el texto de Taberna graba la problemática entrada de España en la órbita de lo global, su radical transformación y el encuentro/desencuentro con el otro, doblemente marcado por centrarse en el inmigrante y en concreto en la mujer inmigrante. A su vez obliga a replantearse el tema de España y a reflexionar sobre la reconfiguración de la nación desde un ángulo polémico y desafiante.

Extranjeras explora la presencia en Madrid de varios colectivos de mujeres inmigrantes procedentes de ámbitos tan diversos como China, India, Ecuador, República Dominicana, Polonia, Rumania, Irán y Marruecos. En palabras de la directora, la cinta muestra "la cara cotidiana y desconocida de otras culturas a través de la experiencia de varias mujeres inmigrantes que viven en Madrid. Descubrimos también los nuevos espacios de intercambio, relación y encuentro que han creado, y el modo en que se adaptan al nuevo entorno para mantener vivas las costumbres que han heredado de sus respectivas culturas" (Taberna, Gara.net 6 noviembre, 2003). El documental se abre con un mosaico de caras formado por una sucesión de imágenes fotográficas dispuestas a modo de retícula y de ahí se pasa progresivamente a los primeros planos de estos rostros plurales que, de forma paulatina, comienzan a parpadear y a cobrar vida. La serenidad que emanan estas imágenes femeninas marca la pauta de la propuesta que este documental encierra respecto a la inmigración, propuesta que pone en tela de juicio la 
imagen de un Madrid conflictivo, alterado por la inmigración y abrumado por las tensiones sociales.

Esta visión de la ciudad como un espacio abierto, poroso e intercultural funciona como imagen especular de la propuesta ética y estética de la directora. En el marco urbano que ella perfila se desdibuja la dicotomía entre nativo e inmigrante ya que el recién llegado monopoliza la pantalla, invirtiendo así la realidad al otorgar una posición central al otro, relegado en la realidad a los márgenes de la sociedad española. Pero a su vez logra mostrar también lo que la ciudad tiene de hostil, hermética y excluyente para estas inmigrantes sin forzar el texto y sin falsear la realidad.

En su acercamiento al Madrid actual Extranjeras logra un perfecto equilibrio entre la problematización y la desproblematización de la figura del inmigrante. El conflicto entre la población española y el otro (las otras en este caso) se subraya y se minimiza a la vez al mostrar la cara oculta de la inmigración, aquella que se aparta de las imágenes violentas y escabrosas a las que nos han acostumbrado los medios de comunicación. A este respecto Isabel Santaolalla (2002) ha resaltado la dicotomía presente en la representación del inmigrante al comparar la presencia de un "otro" exótico y cargado de glamour en los anuncios publicitarios aparecidos en revistas y en la televisión, con presencia de un "otro" victimizado, inmerso en una problemática real y concreta tal y como aparece en el cine. Con la intención de paliar este problema ha surgido una ONG, Xenomedia, dedicada a examinar la representación del inmigrante, que acusa a la prensa y a la televisión de mostrar un Madrid (y una España) problemático y violento, incapaz de lidiar con los procesos migratorios, saturado por la llegada masiva de unos inmigrantes retratados como sujetos amenazantes e incontrolables, resistentes a la integración, 
disruptivos, usurpadores de puestos de trabajo. En contraste con esto la cámara de Taberna se pasea por Lavapiés, Atocha, Puerta de Alcalá, Cibeles, Aluche, Alcobendas y Alcalá de Henares y sitúa en estos barrios diversos colectivos de mujeres inmigrantes centradas en su situación laboral e insertadas pacíficamente en estos espacios. En este recorrido arrastra magistralmente a un espectador poco acostumbrado a este punto de mira, obligándole a replantearse a partir de estas imágenes el significado de la pluralidad cultural. Evita a su vez caer en el error opuesto, el de la idealización, tan común por ejemplo en el ámbito de la publicidad. En una posición intermedia entre la visión denigrante de los medios de comunicación y la mitificadora de la publicidad se localiza Extranjeras, se diría que dispuesta a corregir ambas desviaciones, a atenuar la distorsión.

A partir de la presencia del inmigrante el espacio urbano se somete a un proceso de resignificación y los espacios emblemáticos como (La Cibeles, Atocha y el Retiro) se vacían de su valor tradicional como iconos nacionales y en cierto sentido universales en la medida en que funcionan como símbolos de España reconocibles desde el exterior y se reformulan a partir de la presencia del otro. En este proceso de resemantización, impulsado por la reflexión suscitada a partir de la relación mutua entre el cine y la ciudad, se refleja la disolución de lo nacional y la omnipresencia de lo global. De la dialéctica entre el cine y la ciudad da buena cuenta la siguiente afirmación de Abbas: 'In the first place not only does the cinematic image come out of urban experience; it also incorporates such experience in a new aesthetic principle, an aesthetic of movement where instability becomes paradoxically the principle of structure' (144). Dicha inestabilidad es especialmente significativa en el barrio de Lavapiés, centro neurálgico en lo que atañe a la inmigración. Cabe mencionar que Helena Taberna filmó Extranjeras 
como material de base para su próxima película que en principio se titulará La flor de la canela localizada también en Lavapiés, debido a la atracción que ejerció en la directora la coexistencia en este barrio del Madrid castizo con jóvenes alternativos y con los inmigrantes. $^{3}$

Lavapiés, que adquiere su fisonomía actual en los siglos XVIII y XIX (a pesar de que su ocupación inicial se remonta al siglo XIII) se configuró desde un principio como espacio receptor de emigrantes procedentes de zonas rurales y dedicados a trabajos artesanales y a un comercio básico destinado a abastecer a los habitantes de la zona. Las posteriores olas migratorias vinculadas al despegue industrial de los años 60 y 70 se instalaron en los cinturones industriales de la ciudad de modo que Lavapiés quedó constituido como un reducto atípico. En la actualidad el barrio oscila entre dos polos: por un lado vive sometido a un proceso de rehabilitación encaminado a eliminar la infravivienda y a mejorar los servicios, y por otro funciona como espacio de acogida para inmigrantes cuyos limitados recursos les obligan a acomodarse en estas infraviviendas. Este barrio madrileño cuenta con el mayor porcentaje de población extranjera en términos absolutos y relativos. El número de ocupantes extranjeros censados ha pasado de 6,472 en 1996 a 10.529 en el 2002 y en este último año se contabilizaron 97 nacionalidades. Como muestra el documental, el barrio funciona como exponente de una economía étnica; los comercios de productos alimenticios son el ejemplo más claro. En el 2002 se contabilizaron 407 establecimientos regentados por inmigrantes. ${ }^{4} \mathrm{Y}$ es esta imagen la que busca potenciar Taberna, la de un inmigrante productivo, económicamente solvente, no problemático, emprendedor, con un proyecto de vida compatible con el del resto de los habitantes. La cara que queda oculta es la relacionada con viviendas en condiciones 
de habitabilidad ínfimas (con precios abusivos, causa del hacinamiento), la de un barrio cuyos habitantes, descendientes del ciudadano preindustrial, se resisten a renunciar a su fisonomía tradicional y a compartir su coto privado, la de unos especuladores que luchan por recuperar un suelo urbano de gran valor. Del mismo modo resultan invisibles en el film la tensión derivada de esta convergencia racial, la delincuencia, los abusos perpetrados contra la población inmigrante, la prostitución, etc...

El Retiro suma a su calificación original de espacio de recreo la de punto de encuentro y desencuentro de inmigrantes, sobre todo latinoamericanos. Espacio de intercambio para numerosos grupos que, en un esfuerzo por mantener viva su cultura en una geografía ajena, se reúnen para reinventar su gastronomía, su música, su artesanía, su modo de vida, su identidad. Espacio también de desencuentro y de confrontación con la policía que trata de vetar todo tipo de transacción económica. Espacio de reproche en el que el recién llegado revive el pasado colonial y exige una correspondencia y una legitimación como sujeto postcolonial, apelando a la presencia en Latinoamérica de los españoles que, como ellos apuntan en el film, se llevaron lo mejor de su continente.

Igualmente Aluche se transforma en espacio de intercambio para los inmigrantes polacos que se reúnen los domingos para intensificar los vínculos con su tierra natal, para enviar y recibir paquetes de su país, comprar la prensa polaca, en definitiva para mantener viva su identidad. De aquí pasan a Atocha que suma a su función como nudo de transportes la de espacio de convergencia multicultural. La inestabilidad urbana analizada en estas zonas encuentra su réplica en la imagen fílmica cuyo movimiento reproduce esta mencionada movilidad. 
En el proceso de exploración de este otro Madrid el documental utiliza los medios de transporte como motivo recurrente para hilvanar numerosas secuencias. El metro, el tren el automóvil y los autobuses condensan en su representación la esencia de las metrópolis postmodernas: el monopolio de la tecnología y la omnipresencia de las masas deshumanizadas. A su vez funcionan doblemente como metáfora, por un lado del continuo desplazamiento de la cámara por los más variados espacios madrileños y por otro de este viaje sin retorno inherente a la inmigración. ${ }^{5}$ Por medio de estas repetidas alusiones al movimiento, especialmente aptas para conectar los desplazamientos de la cámara y para subrayar la mencionada correspondencia entre la inestabilidad urbana y el medio fílmico, Taberna potencia la cohesión de su texto y minimiza la fragmentación inevitable en este tipo de documental.

En contraste con estas tomas deshumanizadas de Madrid (calles invadidas por el tráfico, fuentes, estaciones de trenes y de metro, coches circulando de noche...) se muestran los lugares ocupados por inmigrantes como espacios humanizados. El Madrid dinámico y esperanzador que el film proyecta resulta ser el habitado por las recién llegadas, vivas dentro de su marginalidad, decididas a inventar una vida mejor y a superar los obstáculos. Esta sustitución en el celuloide del madrileño por el recién llegado obliga al espectador a replantearse su país, a dar cabida a un otro que desmonta con su modo de vida la retórica de la invasión y de la ola amenazante. ${ }^{6}$

Desde la perspectiva de Taberna se ensalza la otredad, esta otredad doble (inmigrante-mujer) que he mencionado al comenzar este estudio. La directora piensa Madrid en femenino desafiando en el proceso la noción de género. Al otorgar la responsabilidad actancial a estas mujeres plurales y permitirles monopolizar la palabra en 
la pantalla eliminando la tradicional voz en off propia de los documentales, las desplaza de los márgenes al centro. ${ }^{7}$ Junto a esto y en contraste con la imagen tradicional de los movimientos migratorios como fenómeno típicamente masculino se cede aquí el protagonismo a estas mujeres autosuficientes, dispuestas a aferrarse a las posibilidades de independencia que les brinda Madrid y a invalidar los clichés asociados a la dependencia femenina en los países subdesarrollados.

Por encima de la admirable capacidad de la directora para convencer al espectador de la viabilidad de un proyecto multicultural en España y de la necesidad de abrir un espacio para los/las inmigrantes en este Madrid en apariencia tan cosmopolita, emergen una serie de cuestiones inherentes al documental como género que llevan a problematizar la propuesta de Taberna. En primer lugar este documental se sitúa a caballo entre lo que Nichols (2001) define como "documental reflexivo", aquel que en vez de involucrarse sólo en los "actores sociales" se centra también en la representación y la cuestiona desde dentro, y el "documental performativo", cuyo acento se sitúa en el carácter subjetivo de la experiencia y de la memoria. La dimensión reflexiva de Extranjeras remite a una desfamiliarización intencionada del fenómeno de la inmigración, a una representación que se aparta de los parámetros convencionales de esta experiencia (conflictividad, violencia, marginalidad, crimen); la performativa alude por un lado a la voluntad por parte de la directora de dejar a los personajes proyectar su propia subjetividad y por otra a su capacidad para reinventarla. A su vez esta dimensión de 'performance' tal y como la ha planteado Scheibler, incorpora otra vuelta de tuerca que desestabiliza el sentido de lo real asociado a este tipo de textos: la actuación. Para él los documentales en general contienen una serie de 'momentos de actuación' que permiten poner en tela de juicio la 
autenticidad y el carácter de documento asociado a estos textos. Según Scheibler 'these performative moments which deconstruct documentary erupt when the fictional aspects and the nonfictional collide' (66). Dicha convergencia entre lo verdadero y lo ficticio se plasma claramente en Extranjeras. Varias de estas mujeres exhiben una plena conciencia de su protagonismo como actrices en este film. La sudanesa propietaria de la peluquería, las integrantes del grupo Afrika Lisanga, estas últimas doblemente actrices, representan un papel creado por ellas mismas, un guión individual que les permite proyectar la imagen elegida. Igualmente la mencionada sustitución de la tradicional voz en off de los documentales por la intervención directa de las protagonistas les invita en cierta medida a construir su propio personaje y a manipular la imagen que quieren proyectar. A pesar de resultar obvia la existencia de un 'guión - cuestionario' previo al que se ciñe el discurso de estas mujeres, se transparenta por debajo de él una búsqueda de espontaneidad y una relativa diversidad de puntos de vista. Sin pretender minar con ello la autenticidad del documental resulta iluminador tener en cuenta que la inmigración fuerza al inmigrante a reconstruir su propia imagen y a representar un papel adecuado a su nueva realidad. La necesidad de reinventarse a sí mismas que experimentan estas mujeres al insertarse en una nueva cultura es fundamental para captar esta señalada dimensión de 'performance' y este punto de fricción entre la realidad y la ficción.

Otro desafío que cabe plantear a Extranjeras procede del ámbito de los estudios coloniales. A la luz de los mismos destaca la pervivencia de estructuras de poder heredadas del pasado colonial, concretamente la construcción de la imagen del inmigrante desde la perspectiva del sujeto dominante que ha condicionado la construcción del otro desde el siglo XV hasta el presente. Como espectadores 
observamos que el punto de vista narrativo, a pesar de la intervención directa de las inmigrantes, pertenece a una observadora inscrita en una tradición cultural ajena a la vivida por las protagonistas de este documento. Al margen de la empatía de Helena Taberna con ellas y de su grado de compromiso con su problemática, su perspectiva como habitante del país receptor difiere inevitablemente de la de los sujetos representados. A esta cuestión aluden Gayatri Spivak y Sneja Gunew en su debate sobre post-colonialismo, anti-imperialismo y multiculturalismo al afirmar que: 'The whole notion of authenticity, of the authentic migrant experience, is one that comes to us constructed by hegemonic voices' (Harasim, 61) corroborando el 'decalage' entre el sujeto enunciador y el objeto de la enunciación.

Aunque la cuestión de la representación del otro desde la cultura hegemónica no constituye el objetivo central de este trabajo, me interesa destacar cómo Extranjeras minimiza la presencia de la directora eliminando la voz en off y presentando una serie de posiciones lo suficientemente diversas como para no asociarlas a una postura unidimensional concreta. Con este propósito trata de abrir un espacio para que el otro se construya a sí mismo, ocultando la voz hegemónica detrás de estas mujeres y reduciendo la fricción entre el discurso dominante y el del inmigrante.

Hemos de recordar que en el cine español apenas existen textos sobre la inmigración creados por inmigrantes. A diferencia por ejemplo de Francia, Bélgica, Holanda, Alemania, Luxemburgo, Suiza, Canadá y Estados Unidos que producen o coproducen un buen número de films dirigidos por cineastas de diverso origen étnico y que cuentan con un amplio repertorio de obras literarias escritas desde esta perspectiva, España cuenta exclusivamente con una representación del otro desde el punto de vista del receptor. ${ }^{8}$ El 
sujeto inmigrante es narrado desde fuera y en consecuencia queda excluido de la producción de significado tanto a nivel de la creación como de la recepción. Falta aún un largo recorrido para que el inmigrante se sitúe detrás de la cámara y no delante y se siente como espectador crítico en la butaca de los cines. En este sentido Silvia Bermúdez nos recuerda que 'only immigrants can voice the harrowing experiences of transatlantic and transnational journeys and because they belong in this case to the first generation of immigrants little or not cultural texts are usually produced until the second generation' (179). El inmigrante, como apunta Bermúdez, 'does not speak but is represented and thus, ultimately, witnessed'-mostrado- (179). No obstante, a pesar de su voluntad de ceder la palabra estas mujeres y de minimizar la distancia entre la cámara, la directora y ellas se transparenta la mirada del sujeto dominante, que inevitablemente filtra el texto a través de su experiencia y de su cultura. A diferencia de los documentales sociales tradicionales en los que la distancia entre el autor y el sujeto representado se intensifica en la medida en que subrayan la diferencia entre el sujeto representado y el director, en Extranjeras se desvela el esfuerzo de la directora por borrar la diferencia entre sus personajes y el resto de los españoles. Una muestra clara de esta postura conciliadora es la presencia de la directora en la pantalla al final del film, mezclada con un grupo de inmigrantes en un canto común, parece responder a este esfuerzo de la directora por acortar la distancia.

El cine como práctica cultural constituye una especie de evidencia empírica para comprender el espacio urbano de ahí la necesidad de explorar el impacto que este medio tiene en la ciudad y el que la ciudad tiene en él, en concreto el efecto del cine a la hora de entender la transformación de la ciudad. Pero esta evidencia no emerge solo a partir de 
las imágenes visuales sino a partir de las reflexiones que éstas suscitan y de la crítica de las mismas. En otras palabras el impacto del texto fílmico que nos ocupa deriva de la convergencia entre el discurso verbal/visual que configura Extranjeras a caballo entre lo performativo y reflexivo, y el discurso crítico que genera. Si como señala Stuart Hall la identidad nacional es 'a production, which is never complete, always in process, and always constituted within, no outside, representation' (68) los productos culturales como Extranjeras funcionan como piezas clave en este continuo proceso de reconstrucción de la identidad española.

El ensamblaje de un nuevo Madrid receptor de inmigrantes plasmado en este documental encierra en sí mismo el mensaje esperanzador que Taberna quiere transmitir al recrear una ciudad plural, capaz de absorber (si no de integrar) con relativa armonía al recién llegado. La sustitución de una imagen dislocada del inmigrante, perfilada a partir de su victimización o de su criminalidad, por una visión de su acoplamiento y de su relativa integración laboral (a pesar de vivir una cultura del gueto) abre paso a una percepción más abierta e inclusiva de la otredad. La presencia del otro a la hora de reinterpretar la España moderna y global pasa a ser un componente esencial e imprescindible para delinear el futuro del país. Extranjeras nos obliga a reimaginar Madrid a partir de la mirada del otro, del recién llegado, a la vez ajeno y cercano, vinculado a un pasado que flota sobre la memoria colectiva, portador de otra historia. ${ }^{9}$ Un otro representado aquí como parte integrante del mosaico español que lleva a replantearse las nociones de nacionalidad, género, clase social, ciudadanía y pertenencia y a entender la tensión entre lo local, lo nacional y lo global como un debate abierto, articulado a partir de unos parámetros inestables, en continuo proceso de reformulación. Como afirma 
Abbas 'It is exactly the instability of the cinematic image that allows it to evoke the city in all its errancy in ways that stable images cannot' (145). 


\section{NOTAS}

1- Tomo el dato del trabajo de George Mariscal 'The Role of Spain in Contemporary Race Theory' . Arizona Journal of Hispanic Cultural Studies 2 (1998): 7-22.

2- Se han publicado recientemente numerosos artículos sobre la representación de la inmigración en el cine y en la literatura españoles. Destacan los trabajos de Isabel Santaolalla, Daniela Flesler, Silvia Bermúdez, David Corkill, Yolanda Molina, Juan Goytisolo, Sami Nair, Luis Martín Cabrera, Núria Triana Toribio, Joseba Gabilondo, Carmen Urioste etc. El País dedica también un suplemento dominical a la inmigración el 16 de julio de 2002. En cuanto a publicaciones referidas a inmigración en el cine extranjero destaca el valioso trabajo de Hamid Naficy, $A n$ Accented Cinema, centrado en el cine dirigido y producido por exiliados, inmigrantes, y otros seres asociados a varios tipos de diáspora. En lo relativo al tema de la inmigración en la literatura española destaca la publicación de Irene Andrés Suárez et al. titulada La inmigración en la literatura española contemporánea.

3- De momento parece que Helena Taberna ha decidido posponer la filmación de $L a$ flor de la canela.

4- Los datos proceden de un trabajo presentado en la Universidad de California, Davis en mayo del 2004 por Alberto Riesco del Departamento de Sociología de la Universidad Complutense.

5- Stuart Hall destaca la imposibilidad de retorno para el inmigrante, las radicales transformaciones sufridas en el proceso que impiden el reencuentro con el país de 
origen y que van más allá del viaje de vuelta planteado en términos geográficos. Como él apunta 'Migration is a one way trip. There is not home to go' (135).

6- María Pilar Rodríguez en su estudio sobre Extranjeras explora en detalle la propuesta que encierra el documental de Taberna, su originalidad formal y la enorme eficacia de este texto visual a la hora de analizar la realidad de estas mujeres inmigrantes.

7- En su estudio sobre el documental cinematográfico Nichols subraya como uno de sus rasgos definitorios la presencia de una voz en off que impone y determina el punto de vista del texto. Dicha voz no existe en el documental de Taberna y en su lugar se cede la palabra a las protagonistas de esta historia.

8- Para una información detallada de los documentales y películas dirigidas por inmigrantes, exiliados y sujetos que ha vivido una diáspora consultar la siguiente página: http://www.africanfilm.com/cat3.htm). En el caso de España parece que existe un documental sobre Lavapiés dirigido por un profesor egipcio aunque desafortunadamente no he logrado comprobar el dato.

9- Madrid como objeto de representación en el cine español ha recibido abundante atención por parte de la crítica. Destacan en esta temática los trabajos de Pascual Cebollada y Mary Santa Eulalia Madrid y el cine. Panorama filmográfico de cien años de historia, de Kathleen Vernon, 'Crossing City Limits: Fiction, Documentary, History in Basilio Martín Patino’s Madrid' (1995) además de un número extraordinario de Nickelodeón 7 (1997). Madrid y el cine en el que directores, críticos y escritores reflexionan sobre Madrid y el cine en una serie de 
artículos diversos: los cines de Madrid, temas dominantes en el cine centrado en Madrid etc... 


\section{OBRAS CITADAS}

Abbas, Ackbar, 2003. 'Cinema, the City and the Cinematic' in Global Cities, ed. Linda Krause and Pratrice Petro (New Brunswick, New Jersey and London: Rutgers University Press), pp. 142-156.

Andrés-Suárez, Irene, Marco Kunz e Inés d'Ors, 2002. La inmigración en la literatura española contemporánea. (Madrid: Verbum).

Ballesteros, Isolina (2001). Cine (ins)urgente (Madrid: Fundamentos).

Bermúdez, Silvia, 2001. 'Rocking the Boat: The Black Atlantic in Spanish Pop Music from the 1980's and the 90's', Arizona Journal of Hispanic Cultural Studies, 5: 177193.

Cebollada, Pascual y Mary Santa Eulalia, 2001. Madrid y el cine. Panorama filmográfico de cien años de historia. (Madrid: Consejería de Educación de la Comunidad de Madrid).

Corkill, David, 2000. 'Race, immigration and multiculturalism in Spain' in Contemporary Spanish Cultural Studies, ed. Barry Jordan and Rikki MorganTamosunas (London: Verso), pp. 48-57.

Flesler, Daniela, 2001. 'De la inmigración marroquí a la invasión mora: discursos pasados y presentes del (des) encuentro entre España y Marruecos', Arizona Journal of Hispanic Cultural Studies, 5: 73-88.

Fox, Iman, 1998. La invención de España (Madrid: Cátedra).

Goytisolo, Juan y Nair, Sami, 2000. El peaje de la vida (Madrid: Aguilar).

Gabilondo, Joseba 'On the Hispanic Atlantic Intersection of Postcoloniality, Postnationalism and Globalization' in Brokering Spanish Post nationalism, ed. Teresa Vilarós et al. Forthcoming.

Hall, Stuart, 1997. 'Minimal Selves', in Studying Culture, ed. Ann Gray and Jim Mcguigan (London: Verso), pp. 134-138.

Harasim, Sara, ed.,1990. The Post-Colonial Critic. Gayatry Chakravorty Spivak (New York: Routledge).

Hooper, John, 1995. Los nuevos españoles (Madrid: Vergara). 
Kinder, Marsha, 1997. 'Documenting the National and Its Subversion in a Democratic Spain' in Refiguring Spain, ed. Marsha Kinder (Durham and London: Duke University Press), 65-98.

Mariscal, George, 1998. 'The Role of Spain in Contemporary Race Theory', Arizona Journal of Hispanic Cultural Studies, 2: 7-22.

Martín-Cabrera, Luis, 2002. 'Postcolonial Memories and racial violence in Flores de otro mundo', Journal of Spanish Cultural Studies, 3.1: 43-56.

Molina Gavilán, Yolanda, 2001. 'Policing Spanish/European Borders: Xenophobia and Racism in Contemporary Spanish Cinema'. http://www.lehman.cuny.edu/ciberletras/vo5/molina.html

Naficy, Hamid, 2001. An Accented Cinema (Princeton: Princeton University Press).

Nichols, Bill, 2001. Introduction to Documentary (Bloomington and Indianapolis: Indiana University Press).

---. Blurred Boundaries. Bloomington and Indianapolis: Indiana University Press, 1994.

Nickel Odeón 7, 1997. Madrid y el cine (Madrid: Nickel Odeon Dos)

Pino del, José Manuel (1999). El Hispanismo en los Estados Unidos (Madrid: Visor).

Richardson, Bill (2001). “Hispanic v. European Identity: Where is Spain?”. Spanish Studies. (London: Arnold). (3-21)

Rodríguez, María Pilar. 'Extranjeras'.

(www.lamiaproducciones.com/extranjeras/textompilar.htm)

Santaolalla, Isabel, 2002. 'Ethnic and Racial Configurations in Contemporary Spanish Culture' in Constructing Identity in Contemporary Spain, ed. Jo Lanbayi (Oxford University Press), pp. 55-71.

Santaolalla, Isabel, 1999. “Close Encounters: Racial Otherness in Imanol Uribe's Bwana”. BHS, 76: 111-122.

Scheibler, Susan, 1993. 'Constantly Performing the Documentary: The Seductive Promise of Lightning over Water' in Theorizing Documentary, ed. Michael Renov (New York and London: Routledge), pp. 146-149.

Smith, Paul Julian (2000). The Moderns. (Oxford: Oxford University Press). 
Taberna, Helena. Gara-net. 6 noviembre, 2003.

(www.gara.net/orriak/P06112003/art59133.htm)

Triana Toribio, Núria, 2003. Spanish National Cinema (London and New York: Routledge).

Urioste, Carmen, 2000. 'Migración y racismo en el cine español', Monographic Review/Revista Monográfica 15: 44-59.

Vernon, Kathleen, 1995. 'Crossing City Limits: Fiction, Documentary, History in Basilio Martín Patino's Madrid’, Cine-Lit II : 175-185. 